\title{
Dynamic Mechanical Properties and Energy Dissipation Analysis of Sandstone after High Temperature Cycling
}

\author{
Qi Ping $\mathbb{D}^{1,2,3}$ Chuanliang Zhang, ${ }^{1,2,3}$ Hongjian Sun, ${ }^{1,2,3}$ and Xu Han ${ }^{2,3}$ \\ ${ }^{1}$ State Key Laboratory of Mining Response and Disaster Prevention and Control in Deep Coal Mine, \\ Anhui University of Science and Technology, Huainan, Anhui 232001, China \\ ${ }^{2}$ Research Center of Mine Underground Engineering, Ministry of Education, Anhui University of Science and Technology, \\ Huainan, Anhui 232001, China \\ ${ }^{3}$ School of Civil Engineering and Architecture, Anhui University of Science and Technology, Huainan, Anhui 232001, China
}

Correspondence should be addressed to Qi Ping; ahpingqi@163.com

Received 22 May 2020; Revised 17 June 2020; Accepted 24 June 2020; Published 10 July 2020

Academic Editor: Bangyou Jiang

Copyright $(2020$ Qi Ping et al. This is an open access article distributed under the Creative Commons Attribution License, which permits unrestricted use, distribution, and reproduction in any medium, provided the original work is properly cited.

In order to study the effect of high temperature cycling on the physical and mechanical properties of rock materials, a box-type resistance furnace was used to conduct high temperature cycling at $400^{\circ} \mathrm{C} 10$ times on sandstone specimens in coal mine, and the impact compression tests under 8 loading rates were carried out using a split Hopkinson bar (SHPB) device. Results showed that, with the increase of cycle times, the gray white sandstone specimen gradually showed reddish brown spots, and the volume of specimen increased, while the mass, density, and longitudinal wave velocity decreased; in addition, the volume increase rate, the mass decrease rate, the density decrease rate, and the longitudinal wave velocity decreased rate with cycle times showed quadratic function relationship. The dynamic compressive stress-strain curve of sandstone specimens subjected to high temperature cyclic action under impact load was obviously different from that under normal temperature. The dynamic elastic modulus was obviously larger than that under static load. The failure mode of dynamic and static specimens showed brittleness and ductility characteristics, respectively. In the SHPB test, the impact pressure, reflected energy, transmitted energy, and absorbed energy of the rock specimen all increased linearly with the increase of incident energy. The dynamic compressive strength, elastic modulus, and strain rate of sandstone specimens were positively correlated with the incident energy, while the dynamic strain showed negative correlation.

\section{Introduction}

As a kind of brittle material, rock is a complex solid material widely existing in nature and formed by the aggregation of heterogeneous mineral components. With the gradual depletion of shallow mineral resources, deep mining has become the development trend in mining engineering, and the mining depth of many mines has reached more than $1200 \mathrm{~m}$. However, factors such as high stress, high temperature, and high water pressure in deep mining process make it more difficult to mine resource, worsen the working environment, and sharply increase the production cost $[1,2]$. In the high temperature environment of deep underground rock mass, mechanical driving and blasting impact the effect of the coexistence of force and cyclic high temperature. The rock will be destroyed under the combined action of external forces and high temperature. In the deformation and failure process of rock, material and energy are constantly exchanged with the outside environment [3]. Therefore, damage evolution in rock material can be reflected from the perspective of energy dissipation.

At present, many experimental studies have been carried out on the mechanical properties of rocks under high temperature [4]. Under static mechanics, Chen et al. [5] used hydraulic servo test system to conduct experimental research on the mechanical properties of granite after $20^{\circ} \mathrm{C}$ to $1000^{\circ} \mathrm{C}$; found the change rules of peak stress, peak strain, and elastic modulus; and obtained the regression formula of the changes of the three properties with temperature through regression analysis. Du et al. [6] conducted experimental 
research on the mechanical properties of granite at the temperature of $20^{\circ} \mathrm{C}$ to $800^{\circ} \mathrm{C}$; analyzed the variation rules of stress-strain curve, peak stress, peak strain, elastic modulus, and Poisson's ration of granite; and found that $400^{\circ} \mathrm{C}$ is the critical temperature for the change of mechanical properties of granite. Zhu et al. [7] studied the change rule of peak stress, peak strain, and elastic modulus of three kinds of rocks at $20^{\circ} \mathrm{C}$ to $800^{\circ} \mathrm{C}$ by the uniaxial compression test. Test results indicated that the mechanical properties of rocks after high temperature are not only related to the temperature experienced, but also closely related to the cooling mode after high temperature. $\mathrm{Su}$ et al. [8] carried out X-ray diffraction, electron microscope scanning, and uniaxial compression tests on the fine sandstone at $400^{\circ} \mathrm{C}$ to $1000^{\circ} \mathrm{C}$, and the correlation between the mineral composition, structural characteristics, and mechanical parameters of the sample at high temperature was investigated. Results showed that $600^{\circ} \mathrm{C}$ was the turning temperature of the strength and deformation. When the high temperature exceeded $400^{\circ} \mathrm{C}$, peak strain increased monotonously with the increase of temperature. Mao et al. [9] conducted uniaxial compression tests under different loading rates for mudstone from room temperature to $400^{\circ} \mathrm{C}$; the changes of stressstrain curve, peak stress, elastic modulus, and fracture form of mudstone at high temperature with different loading rates were analyzed. The research shows that when the temperature increases from room temperature to $400^{\circ} \mathrm{C}$ and the loading rate is less than $0.03 \mathrm{~mm} / \mathrm{s}$, the peak strength decreases with the loading rate. When the loading rate exceeds this value, the peak strength shows different performances. When the loading rate is $0.03 \mathrm{~mm} / \mathrm{s}$ at room temperature, the elastic modulus decreases at the first time and then increases with the loading rate. Between $200^{\circ} \mathrm{C}$ and $400^{\circ} \mathrm{C}$, the elastic modulus decreases with the increase of the loading rate. With the increase of loading rate, the number of debris flows in mudstone increases. Under high loading rate, the mudstone specimens at different temperatures show a conical failure mode. Zhang et al. [10] studied the influence of temperature $\left(25^{\circ} \mathrm{C}\right.$ to $\left.500^{\circ} \mathrm{C}\right)$ on the physical and mechanical properties of rocks. The study showed that at the stage of $100^{\circ} \mathrm{C}$ to $500^{\circ} \mathrm{C}$, the porosity, permeability, and sound emission of rocks increase significantly, while the wave velocity kept decreasing. Under the temperature of $200^{\circ} \mathrm{C}-500^{\circ} \mathrm{C}$, the physical and mechanical properties of rock, such as compressive strength, tensile strength, permeability, and wave speed, will change significantly. Within the temperature range of $400^{\circ} \mathrm{C}$ to $500^{\circ} \mathrm{C}$, the properties of rock increase rapidly with the increase of volume, while the tensile strength, compressive strength, and wave speed will decrease. Lü et al. [11] heated the sandstone sample to $900^{\circ} \mathrm{C}$ with a high temperature furnace and then carried out the Brazilian test with a hydraulic universal testing machine to study the longitudinal wave velocity, the total energy absorbed by the disk per unit thickness, and the mass loss rate. The research shows that the tensile strength decreases rapidly in the two stages of $300^{\circ} \mathrm{C}$ to $600^{\circ} \mathrm{C}$ and $800^{\circ} \mathrm{C}$ to $900^{\circ} \mathrm{C}$, and the variation trend of the tensile strength, the longitudinal wave velocity, and the total energy absorbed by the disk per unit thickness is similar with both temperature stages. Sun et al. [12] studied the changes of thermal conductivity, thermal diffusivity, and thermal capacity of sandstone at high temperature heating. The test results show that, from room temperature to $400^{\circ} \mathrm{C}$, the changes correspond to the evaporation of attached water, mixed water, and structural water. In the stage of $400^{\circ} \mathrm{C}-600^{\circ} \mathrm{C}$, especially between $500^{\circ} \mathrm{C}$ and $600^{\circ} \mathrm{C}$, the minerals in sandstone will undergo thermal reaction, which is shown as the increase of porosity, the decrease of conductivity, and the change of heat capacity.

Under dynamic mechanics, $\mathrm{Xu}$ and Liu [13] carried out impact compression test on marble at $25^{\circ} \mathrm{C}$ to $1000^{\circ} \mathrm{C}$ and compared the change rules of peak stress, peak strain, and elastic modulus of marble under different loading rates. The results showed that the peak stress and peak strain of marble at high temperature showed significant strengthening effect of loading rate, while the strengthening effect of loading rate of elastic modulus was not significantly obvious. Yin et al. [14] conducted static and dynamic tests on sandstone at $25^{\circ} \mathrm{C}$ to $800^{\circ} \mathrm{C}$; the results show that, with the increase of temperature, the static and dynamic mechanical properties of sandstone change significantly. The failure modes of rock are splitting failure and tensile failure. The peak strength decreases with the increase of temperature, and the peak strain increases with the increase of temperature. Wang et al. [15] conducted uniaxial dynamic compression tests on sandstone specimens at temperatures ranging from $25^{\circ} \mathrm{C}$ to $1000^{\circ} \mathrm{C}$. The study showed that the dynamic mechanical properties of sandstone specimens changed significantly before and after $100^{\circ} \mathrm{C}$ and $200^{\circ} \mathrm{C}$. At $200^{\circ} \mathrm{C}$, the peak stress and elastic modulus decreased and the peak strain increased rapidly. In addition, the dynamic mechanical properties of sandstone at temperatures higher than $600^{\circ} \mathrm{C}$ deteriorated significantly compared with that at room temperature. Ping et al. [16] studied the dynamic peak stress, dynamic peak strain, dynamic of elastic modulus, and change rule of specimen failure form of sandstone under different impact loads at $25^{\circ} \mathrm{C}$ to $1000^{\circ} \mathrm{C}$. Results show that dynamic elastic modulus decreases with the increase of temperature, and the failure pattern changes from brittle to ductile with the increase of temperature. Wu et al. [17] studied the dynamic uniaxial compression test of sandstone under different loading rates at $25^{\circ} \mathrm{C}$ to $1000^{\circ} \mathrm{C}$, and the results show that the peak strength and loading rate increase by quadratic polynomial, the peak strain and loading rate increase linearly, and the dynamic elastic modulus varies greatly under different temperature scopes.

In respect of high temperature cycle, many scholars have carried out experimental research. Ni et al. [18] used uniaxial rock compression test to study the mechanical properties of marble samples at varying temperatures (i.e., $100^{\circ} \mathrm{C}$ to $600^{\circ} \mathrm{C}$ ) and using different cycle numbers (i.e., 1,10 , and 20 times). The test results show that, with the increase of temperature and cycle times, the failure mode of sample changes from brittle to brittle plastic failure. With the 
increase of cycle times at $600^{\circ} \mathrm{C}$, the peak stress and elastic modulus decrease significantly, while the peak strain increases significantly. Wang et al. [19] used RMT-150C rock mechanics test system to carry out uniaxial and triaxial tests of marble under the action of temperatures of $20^{\circ} \mathrm{C}, 200^{\circ} \mathrm{C}$, and $800^{\circ} \mathrm{C}$ and uniaxial compression tests after temperature cycling. The test results showed that marble's elastic modulus decreased with the increase of temperature. Under the cyclic action of $200^{\circ} \mathrm{C}$, with the increase of the number of cycles, the peak strength and elastic modulus tend to decrease. With the increase of the number of cycles, the longitudinal wave velocity decreases; however, the decrease is much lower than that of longitudinal wave velocity after single heating. Fang et al. [20] used MTS815.03 electrohydraulic servo rock test system to study the stress-strain characteristics of marble under $20^{\circ} \mathrm{C}$ to $800^{\circ} \mathrm{C}$. The test results show that under the same temperature, both the elastic modulus and peak strength of specimens after high temperature cycle are lower than that after one high temperature cycle. Some scholars conducted lots of experimental research on the static mechanical of rock after high temperature, while less study was conducted on dynamic mechanical properties of rock after the high temperature cycle.

In this paper, a box-type resistance furnace was used to conduct high temperature cyclic action of sandstone specimens at $400^{\circ} \mathrm{C} 10$ times, and $50 \mathrm{~mm}$ split Hopkinson pressure bar device was used to conduct impact compression tests at different loading rates on specimens after cyclic. Different loading rates were achieved by adjusting the impact pressure. The impact pressure was set as $0.3 \mathrm{MPa}$,

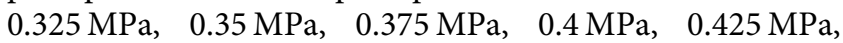
$0.45 \mathrm{MPa}$ and $0.475 \mathrm{MPa}$, respectively. The basic physical properties of sandstone specimens affected by high temperature cycling are discussed, and the dynamic mechanical characteristics and energy dissipation characteristics of sandstone are also considered.

\section{Preparation of High Temperature Sandstone Specimen and Its Basic Physical Properties}

2.1. Rock Sample Selection and Specimen Processing. The selected sandstone is from Gubei Coal Mine, Huainan Mining Group, Anhui Province. In order to reduce the discretization of the test results, a relatively complete rock block was selected as the sampling object, and the bedding direction of the rock was marked; hence, the direction of coring is perpendicular to the bedding direction. In the Rock Mechanics Laboratory of Anhui University of Science and Technology, we finished coring, cutting, and grinding. In order to reduce the errors caused by radial and longitudinal inertia and end friction effect, the sample was machined into a cylinder with a diameter of $50 \mathrm{~mm}$ and a length-diameter ratio of 0.5 , and both ends were carefully polished [21]. The sandstone with similar longitudinal wave velocity was selected to be used as test sample. The average density and velocity of sample sandstone are $2.629 \mathrm{~g} / \mathrm{cm}^{3}$ and $3905 \mathrm{~m} / \mathrm{s}$, respectively.
2.2. High Temperature Cyclic Heating of the Rock Specimen. The heating equipment used in the test is SX-5-12 box-type resistance furnace, equipped with a temperature controller, as shown in Figure 1. Its rated power is $5 \mathrm{~kW}$, rated voltage $220 \mathrm{~V}$, and rated maximum temperature $1200^{\circ} \mathrm{C}$. The resistance furnace workroom is made of silicon carbide sintered, the heating element is made of high temperature resistant wire wrapped in the furnace chamber, and the fireproof insulation material is placed between the workroom and the equipment shell. After the samples were grouped and numbered, they were put into an electric furnace with the size of $300 \mathrm{~mm} \times 200 \mathrm{~mm} \times 120 \mathrm{~mm}$. The average heating rate of the samples was about $10^{\circ} \mathrm{C} / 3 \mathrm{~min}$. After heating to $400^{\circ} \mathrm{C}$, the samples were kept at a constant temperature for $3 \mathrm{~h}$ and then naturally cooled in the furnace to normal temperature, which is defined as one high temperature cycle; the temperature change curves during heating process are shown in Figure 2. The samples were heated 10 times in high temperature cycle.

2.3. Apparent Morphology of the Specimen. The apparent morphology of sandstone specimens at normal temperature and after natural cooling to normal temperature after $2,4,6,8$, and 10 cycles of action at $400^{\circ} \mathrm{C}$ is shown in Figure 3.

As seen from Figure 3, the sandstone specimen is grayish white at room temperature, and with the increase of cyclic times at $400^{\circ} \mathrm{C}$, reddish brown spots gradually appear on the surface of the specimen.

2.4. Mass, Volume, and Density of the Specimen Varied with the Number of High Temperature Cycles. The mass, diameter, and height of the specimen at room temperature and after different cycles under $400^{\circ} \mathrm{C}$ were recorded. The precision of the electronic precision balance was $0.001 \mathrm{~g}$. The mass of the specimen varies with the number of cycles at high temperature, as shown in Figure 4.

It can be seen from Figure 4 that the mass of the specimen decreases with the increased number of high temperature cycles. After $2,4,6,8$, and 10 cycles of $400^{\circ} \mathrm{C}$, the specimen mass decreases by $0.74 \%, 0.92 \%, 1.05 \%$, $1.08 \%$, and $1.14 \%$ compared with the normal temperature (without high temperature cycle), respectively. After two cycles of high temperature, the mass loss range was obvious, the mass loss tended to be flat after 2-6 cycles, and the mass loss was very small after 8-10 cycles. It was determined that the reason for this mass reduction is that, after two cycles of high temperature, the sandstone specimen changes from normal temperature state to high temperature state. The damage in the process of temperature rise causes the particles on the surface of the specimen to peel off slowly, and the free water inside gradually evaporates and is lost. The main reason for loss of mass is the particles on the surface of the specimen falling off from 4 to 6 times. After 8-10 times, exterior and interior of sandstone samples tend to be stable. 


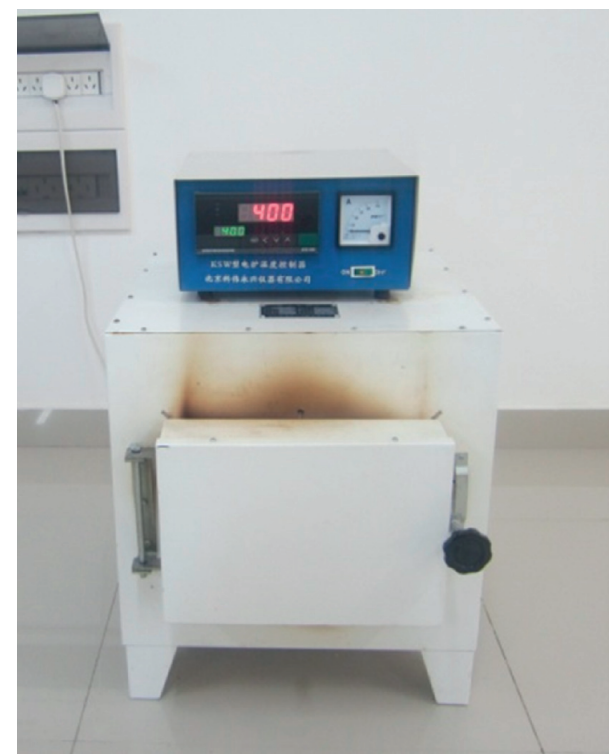

FIgURE 1: Box-type resistance furnace.

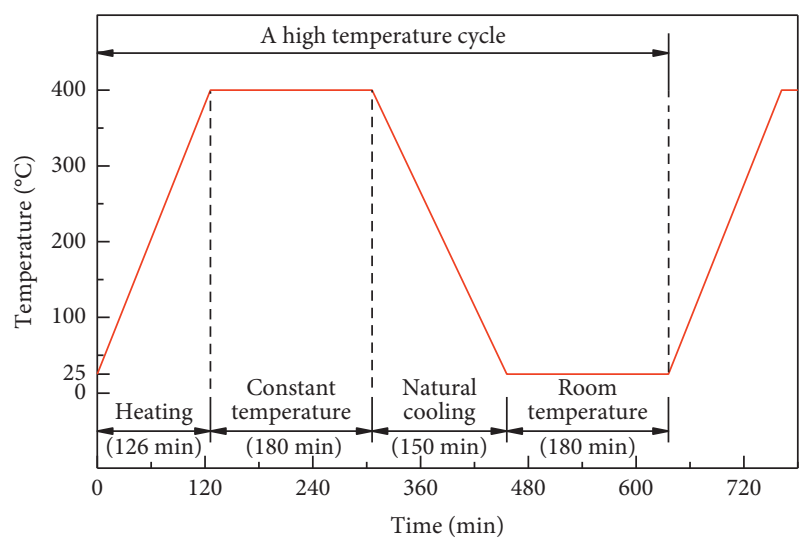

FIgURE 2: Temperature change curves during heating process.

The mass reduction rate was fitted with the number of cycles, and the fitting relationship is shown as follows:

$$
M^{\prime}=-0.005 n^{2}+0.118 n+0.534, \quad R^{2}=0.9830,
$$

where $M^{\prime}$ is the mass reduction rate of the specimen, $\% ; n$ is the high temperature action cycle number.

The change of specimen volume with the number of cycles at high temperature is shown in Figure 5.

Figure 5 shows the volume increase rate of the specimen with the increase of the number of cycles, while the amplitude is not large. After $2,4,6,8$, and 10 cycles at $400^{\circ} \mathrm{C}$, the specimen volumes increased by $0.01 \%, 0.05 \%, 0.08 \%, 0.16 \%$, and $0.22 \%$, respectively, compared with the normal temperature. This shows that in the process of high temperature cyclic heating, the size of the specimen continues to expand throughout each high temperature cycle and has a growing trend from weak to strong.

The volume increase rate is fitted with the number of cycles. The fitting relation is shown as follows:

$$
V^{\prime}=0.001 n^{2}+0.007 n-0.010, \quad R^{2}=0.9913,
$$

where $V^{\prime}$ is the volume increase rate of the specimen, \%.

The relationship between the specimen density and the number of cycles at high temperature is shown in Figure 6.

Figure 6 shows that the specimen density decreases with the increase of the number of cycles. After 2, 4, 6, 8, and 10 cycles of $400^{\circ} \mathrm{C}$, the specimen density decreases by $0.80 \%$, $0.94 \%, 1.16 \%, 1.21 \%$, and $1.37 \%$ compared with the normal temperature, respectively. This indicates that the density decreases the most after 2 cycles of high temperature, and the density continues decreasing after 4 to 10 cycles, but the decrease tends to be stable. After 2 cycles, the specimen mass decreases sharply, and the volume of the specimen expands under the action of thermal stress. After 4 to 10 cycles, the mass decreases less and the volume continues to expand, but the volume increases less.

The density reduction rate was fitted with the number of cycles, and the fitting relationship is shown as follows:

$$
\rho^{\prime}=-0.002 n^{2}+0.098 n+0.608, \quad R^{2}=0.9799,
$$

where $\rho^{\prime}$ is the density reduction rate of the specimen, $\%$.

2.5. Law of Wave Velocity Variation of Test Specimen. The C61 type nonmetallic ultrasonic detection instrument is used to measure and calculate the longitudinal wave velocity of the specimen after different high temperature cycles. The change of the longitudinal wave velocity of the specimen with the number of cycles of high temperature is shown in Figure 7.

As can be seen from Figure 7, the longitudinal wave velocity of the specimen decreases with the increase of the number of cycles, and the decrease is large. After 2, 4, 6, 8, and 10 cycles at $400^{\circ} \mathrm{C}$, the longitudinal wave velocity of the specimens decreased by $8.71 \%, 11.79 \%, 12.64 \%, 14.94 \%$, and $16.59 \%$ compared with the normal temperature, respectively. After high temperature cycling, the mineral particles in the rock had different thermal expansion coefficients, which led to uncoordinated thermal expansion among them, with increase of microcracks and void volume, which hindered the propagation of wave velocity. The fitting relation between longitudinal wave velocity reduction rate and number of cycles is shown as follows:

$$
C^{\prime}=-0.025 n^{2}+1.247 n+6.556, \quad R^{2}=0.9799,
$$

where $C^{\prime}$ is the longitudinal wave velocity reduction rate, $\%$.

\section{Dynamic Mechanical Properties and Energy Analysis of Sandstone after High Temperature Cycle}

3.1. SHPB Test Device and Its Basic Principle. The uniaxial compression static and dynamic tests were conducted in the State Key Laboratory of Mining Response and Disaster Prevention and Control in Deep Coal Mine of Anhui University of Science and Technology, as shown in Figure 8. 


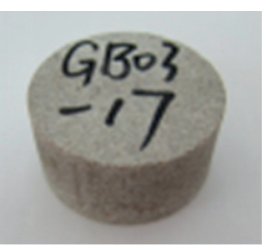

(a)

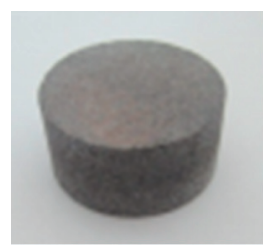

(b)

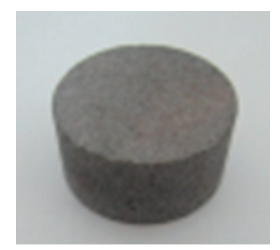

(c)

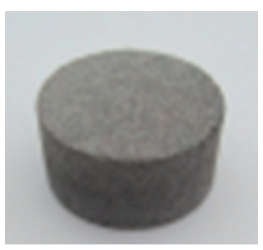

(d)

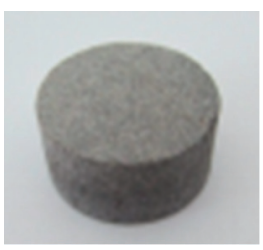

(e)

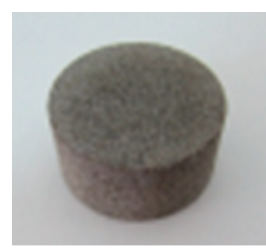

(f)

Figure 3: The apparent morphology of sandstone specimens after the action of cycles at $400^{\circ} \mathrm{C}$. (a) 0 times. (b) 2 times. (c) 4 times. (d) 6 times. (e) 8 times. (f) 10 times.

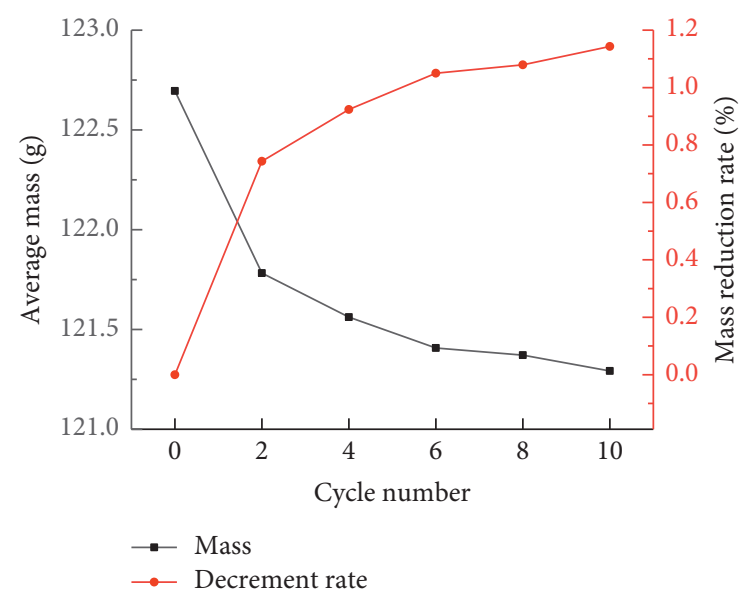

FIGURE 4: The relationship between the mass of specimen and the number of cycles at high temperature.

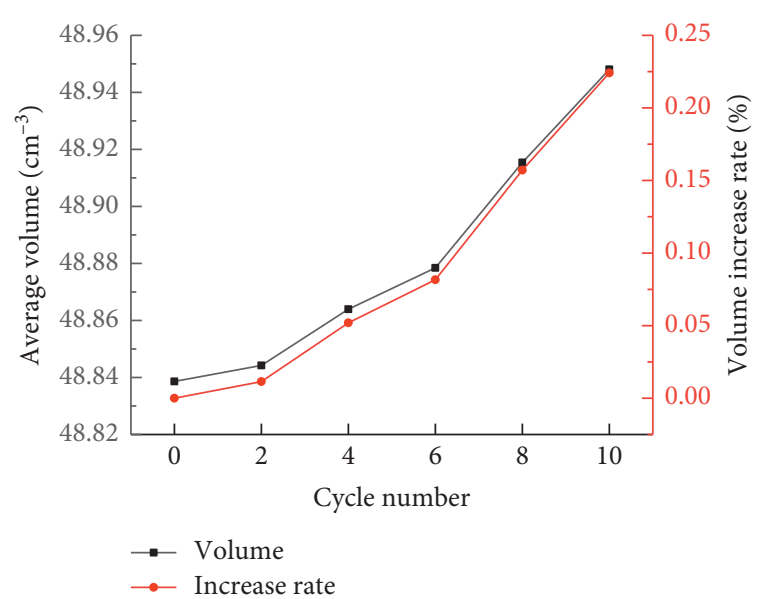

FIGURE 5: The relationship between specimen volume and the number of cycles at high temperature.

The dynamic and static combination SHPB device is composed of an impact loading system and a data acquisition system. The pressure bar material is homogeneous highstrength alloy steel, the ultrasonic wave velocity is $5380 \mathrm{~m} / \mathrm{s}$, the density is $7636 \mathrm{~kg} / \mathrm{m}^{3}$, the diameter is $50 \mathrm{~mm}$, the incident bar length is $2000 \mathrm{~mm}$, the transmission bar length is $1500 \mathrm{~mm}$, and the Poisson's ratio is 0.28 . The impact bar was pressurized with nitrogen.

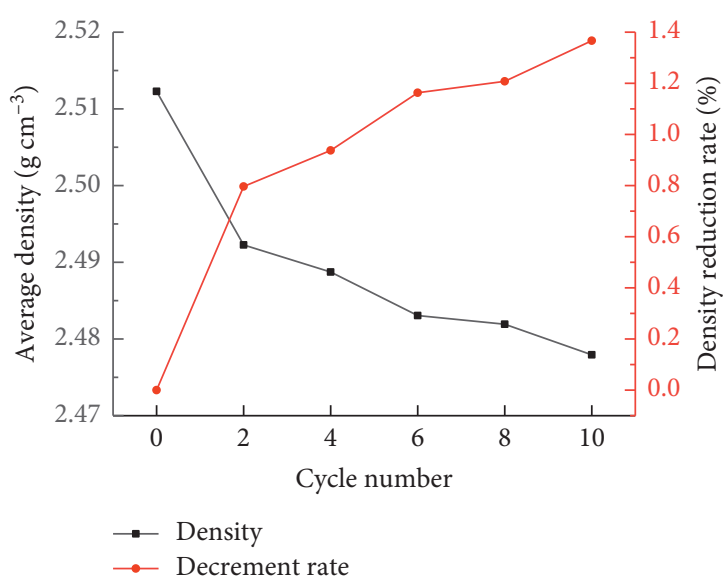

Figure 6: The relationship between specimen density and the number of cycles at high temperature.

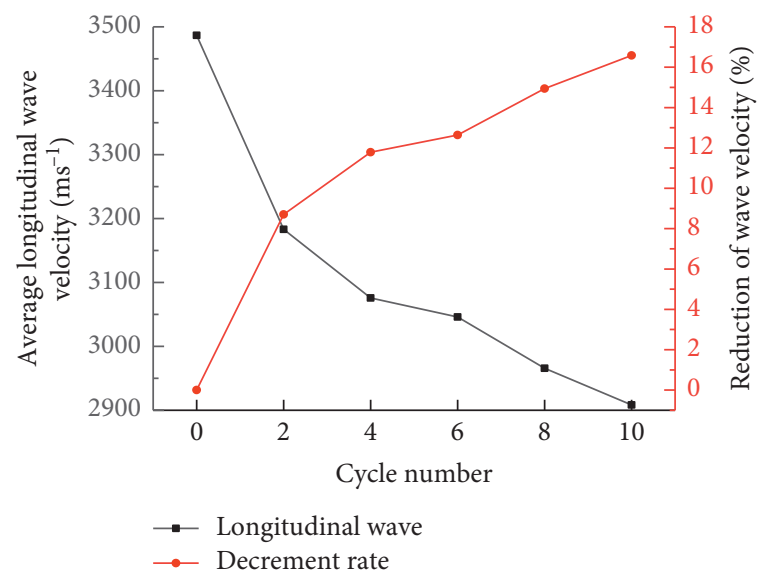

FIGURE 7: The relationship between the longitudinal wave velocity and the number of cycles at high temperature.

SHPB experiment technique is based on two basic assumptions. One is the assumption of one-dimensional stress wave theory, and the other is the assumption of uniform distribution of stress and strain along the sample length. For traditional SHPB experiment, the strain signal is measured by the electric resistance strain film method, and the incident, reflected, and transmitted strains are measured by the strain gauge attached to the surface of the incident and transmitted bars, respectively. The strain gauge test usually 


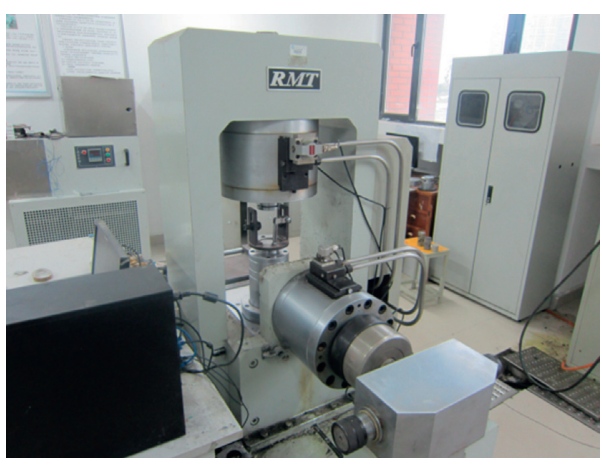

(a)

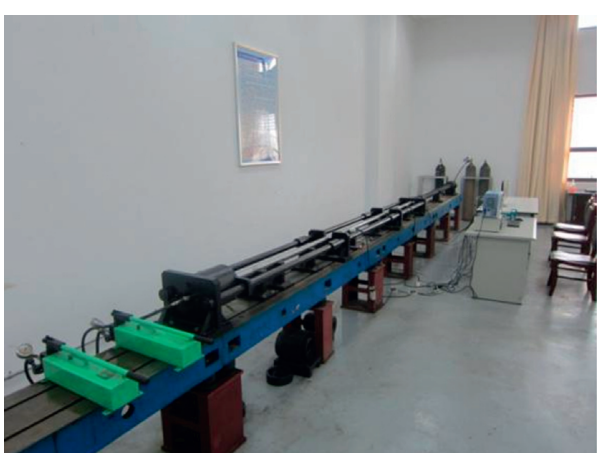

(b)

Figure 8: Static and dynamic test devices. (a) RMT-150B. (b) SHPB system.

uses the testing principle of Wheatstone bridge. The two strain gauges were symmetrically pasted on both sides of the pressure bar and placed on the same cross section of the pressure bar to avoid the influence of the pressure bar bending on the test data and eliminate the interference signal of the nonaxial strain [22]. Based on the basic principle of SHPB test [23], the dynamic strength, dynamic strain, and dynamic elastic modulus of sandstone samples after high temperature cycle were analyzed by using the three-wave method.

\subsection{Analysis of Dynamic Stress-Strain Curve of the Sandstone} Specimen. In order to compare the dynamic compressive strength characteristics of sandstone after high temperature cycling, samples at room temperature without high temperature cycling were selected as the control group, and the static uniaxial compression test was conducted using the RMT-150B rock mechanics test system. The obtained stressstrain curve is shown in Figure 8. Its uniaxial compressive strength of rock is $119.04 \mathrm{MPa}$, and its elastic modulus is $5.42 \mathrm{GPa}$. As can be seen from Figure 9, the stress-strain curve of sandstone specimen under static load roughly goes through three stages. The first stage is the compression phase and the curve is concave. The second stage is the elastic stage, and the deformation of the specimen increases with the increase of the stress. The third stage is the strain softening stage. After the strength exceeds the peak stress, the strain continues to increase but the stress declines until the specimen finally loses its bearing capacity, showing the ductility characteristics.

Figure 10 shows the dynamic stress-strain curves of sandstone specimens under 8 different impact pressures after cyclic action at $400^{\circ} \mathrm{C}$. The dynamic stress-strain curve of sandstone can be divided into three stages: elasticity, yield, and failure stage. Compared with the three stages of sandstone stress-strain curve under static load, the $e$ elastic stages positions are different. Firstly, the dynamic stressstrain curve of sandstone enters the elastic stage directly without going through the compression phase. The stressstrain relationship is approximately positive proportion, and the curve enters the linear state. This is because, compared with the slow loading process of static uniaxial compression,

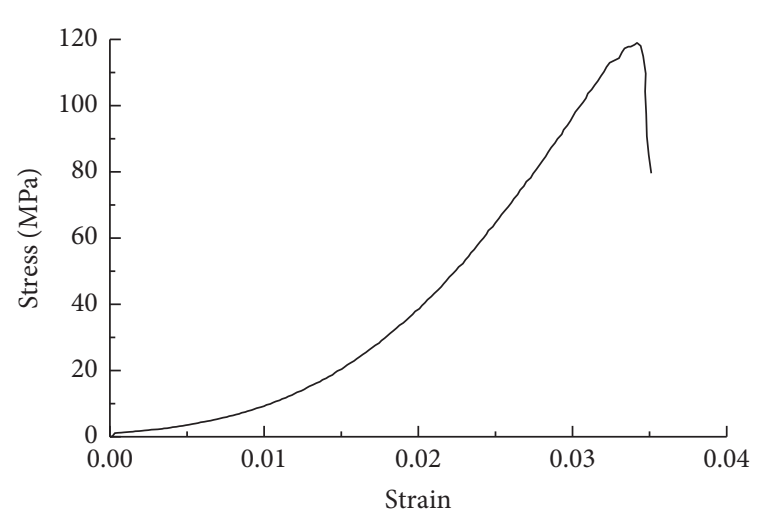

Figure 9: Stress-strain curve of sandstone under static load.

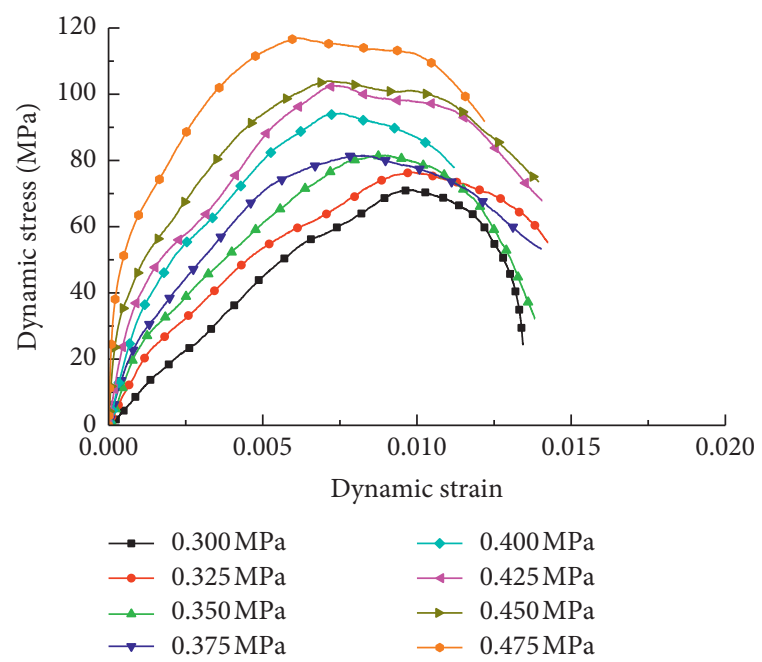

Figure 10: Dynamic stress-strain curve of sandstone.

under the action of high-speed impact loads, the microcracks in sandstone have not yet closed. By comparing the elastic phase of static and dynamic stress-strain curves, it is found that the elastic modulus is larger in the dynamic stress-strain curves. This is mainly because after the highspeed impact load is applied to the sandstone specimen, the specimen will generate the corresponding acceleration. 
According to D'Alembert's principle, the inertia force of the crystal in the sandstone specimen must be involved in bearing the high-speed impact load and resisting deformation, resulting in larger dynamic elastic modulus. Then, the stress-strain curve starts to deviate from the straight line until the peak stress is reached, and the stress-strain curve turns into the yield stage and returns to the curve state. This is because in the elastic stage, with the continuous increase of the stress strain, the microcracks in sandstone expand, the balance of the linear growth of stress strain is broken, and new cracks are generated in the sandstone specimen. Finally, after the peak stress was exceeded, all kinds of microcracks in the sandstone interior formed macroscopic cracks in order to find the deformation space, and the specimen was damaged and thus entered the failure stage. In the failure stage, the slope of the curve is negative, and the curve trend changes from slow to steep. The bearing capacity of the sandstone specimen is rapidly lost, and the brittleness is more and more obvious.

3.3. Energy Composition in the SHPB Test. When the SHPB test device is used to conduct impact compression test on sandstone specimens, the energy carried by incident wave, reflected wave, and transmitted wave can be obtained from (5) during the loading and unloading processes [24]:

$$
\left.\begin{array}{l}
W_{I}(t)=E_{0} C_{0} A_{0} \int_{0}^{t} \varepsilon_{I}^{2}(t) \mathrm{d} t, \\
W_{R}(t)=E_{0} C_{0} A_{0} \int_{0}^{t} \varepsilon_{R}^{2}(t) \mathrm{d} t, \\
W_{T}(t)=E_{0} C_{0} A_{0} \int_{0}^{t} \varepsilon_{T}^{2}(t) \mathrm{d} t,
\end{array}\right\}
$$

where $W_{I}(t), W_{R}(t)$, and $W_{T}(t)$, respectively, represent the incident energy, reflected energy, and transmitted energy.

According to the energy conservation principle, absorbed energy of rock specimens during the impact compression test of SHPB is calculated as follows:

$$
W_{S}(t)=W_{I}(t)-W_{R}(t)-W_{T}(t) .
$$

The absorbed energy of rock $W_{S}(t)$ mainly includes breakage energy $W_{F D}(t)$, ejection kinetic energy $W_{K}(t)$, and other energy dissipation $W_{O}(t)$, such as crack propagation and crack surface in the rock specimen, and microcrack in the fragment; $W_{K}(t)$ is the energy carried by the specimen when it is broken and flies out; $W_{O}(t)$ it is the dissipation energy in various forms including sound energy, heat energy, and radiation energy.

According to the research of Ping et al. [25] and Liu and $\mathrm{Xu}$ [26], $W_{F D}(t)$ accounts for $95 \%$ of $W_{S}(t)$, showing a linear relationship, while $W_{K}(t)$ and $W_{O}(t)$ account for a small proportion in $W_{S}(t)$, and it is relatively difficult to determine. Therefore, in the discussion and analysis, using $W_{S}(t)$ to approximately replace $W_{F D}(t)$ for energy consumption analysis will not have a great impact on the experimental results.

The change of incident energy of sandstone specimen with impact pressure is shown in Figure 11.

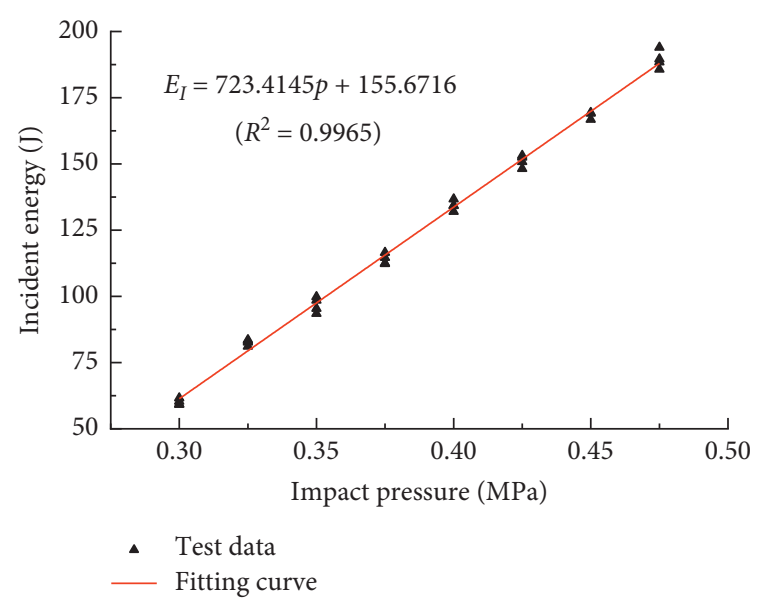

FIgURE 11: The relationship between incident energy and impact pressure.

It can be seen from Figure 11 that the incident energy increases with the increase of the impact pressure, having a strong linear relationship. Therefore, in the following discussion and analysis, the incident energy can be used to approximately replace the impact pressure. From the perspective of energy dissipation, the change rules of the physical indexes such as reflected energy, transmitted energy, absorbed energy, and dynamic mechanical properties of sandstone specimens after the high temperature cycle can be analyzed with the increase of incident energy.

In the impact compression test of sandstone specimen SHPB, the changes of reflected, transmitted, and absorbed energy of the specimen with incident energy are shown in Figure 12.

It can be seen from Figure 12 that both the absorbed energy and the reflected energy of the specimen increase with the increase of the incident energy, showing a strong linear relationship. Moreover, the increasing rate of energy absorbed by the specimen is greater than that reflected by the specimen. The transmitted energy is approximately an upward sloping line with the change of incident energy, which indicates that although the transmitted energy also increases with the increase of incident energy, this effect is not obvious and is closely related to the failure pattern of the specimen.

Since the reflected energy, transmitted energy, and absorbed energy of rock specimen show linear relationship with the incident energy, the fitting relation can be summarized as follows:

$$
W=a W_{I}+b,
$$

where $W$ represents the reflected energy, the transmitted energy, or the absorbed energy by the specimen, and $a$ and $b$ are fitting related parameters. The fitting related parameters of different incident energy are shown in Table 1.

3.4. Dynamic Strength, Strain, and Elastic Modulus of Specimens Change with Incident Energy. The relationship between dynamic strength of sandstone specimens at high temperature and incident energy is shown in Figure 13. 


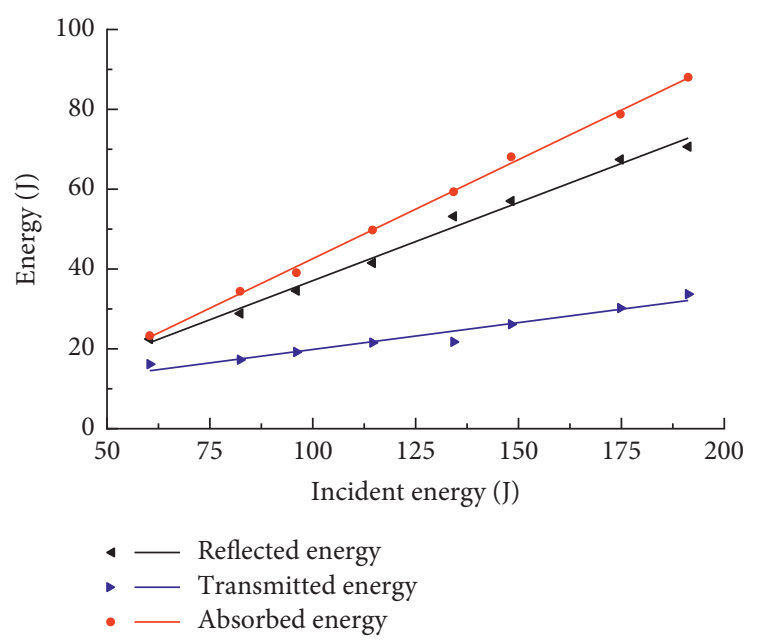

Figure 12: Curve of reflected energy, transmitted energy, and absorbed energy with incident energy.

TABLE 1: Fitting parameters of dissipation energy.

\begin{tabular}{lccc}
\hline Energy category & $a$ & $b$ & $R^{2}$ \\
\hline Reflected energy & 0.391 & -2.068 & 0.9914 \\
Transmitted energy & 0.134 & 6.390 & 0.9532 \\
Absorbed energy & 0.496 & -7.034 & 0.9982 \\
\hline
\end{tabular}

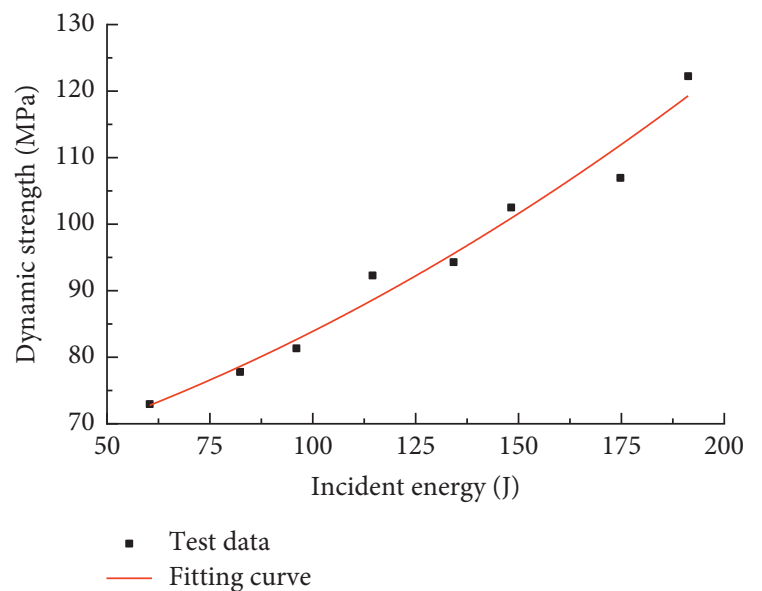

FIgURE 13: Relationship curve between dynamic strength and incident energy.

As can be seen from Figure 13, the dynamic strength of sandstone specimens $\left(\sigma_{T}\right)$ after the high temperature cycle increases with the change of incident energy $\left(W_{I}\right)$ approximately in a quadratic polynomial function, and the fitting relation is

$$
\sigma_{T}=8.213 \times 10^{-4} W_{I}^{2}+0.148 W_{I}+60.796, \quad R^{2}=0.9783 .
$$

Within the incident energy range of 60.4 to $191.2 \mathrm{~J}$, the dynamic strength continued increasing from $72.96 \mathrm{MPa}$ to 122.24 MPa, showing a positive correlation of quadratic function. In the process of high temperature circulating, heating due to dehydration effect of rock particles is not easy to slip, high temperature thermal expansion causes the rock mineral porosity to decrease, and rocks become dense, resulting in the increase of strength [27].

As one of the important indexes for measuring rock deformation parameters, strain has important reference significance. The change of dynamic strain of sandstone specimen with incident energy after high temperature cycle is shown in Figure 14.

It can be seen from Figure 14 that the relation between the sandstone specimen strain and incident energy decreases as a quadratic function. Within the range of incident energy of 60.4-191.2 J, the strain continued to decrease, from $9.74 \times 10^{-3}$ to $6.39 \times 10^{-3}$, with $34.39 \%$ decrease ratio. With the incident energy boundary of $134.2 \mathrm{~J}$, when the incident energy is greater than $134.2 \mathrm{~J}$, the decline rate of the strain curve is obviously greater than the previous decline rate. This is because, with the increase of incident energy, the primary fractures in sandstone specimens are fully developed, and the rock damage caused by structural thermal stress generated by high temperature cycling rapidly fills the primary fractures in sandstone specimens, and the dynamic strain decreases. The larger the incident energy is, the more obviously the strain decreases.

The strain of the specimen $\left(\varepsilon_{T}\right)$ is fitted with the incident energy $\left(W_{I}\right)$. The fitting relation is shown as follows:

$$
\varepsilon_{T}=-1.796 \times 10^{-4} W_{I}^{2}+0.016 W_{I}+9.521, \quad R^{2}=0.9520 .
$$

Elastic modulus is an important mechanical parameter of rock, which reflects the deformation property of rock in the elastic stage. The relationship between dynamic elastic modulus of sandstone specimen and incident energy after high temperature cycle is shown in Figure 15.

It can be seen from Figure 15 that the dynamic elastic modulus of sandstone specimen is positively correlated with the incident energy as a quadratic function. With the increase of incident energy, the dynamic elastic modulus of sandstone specimen increases gradually, and the increase speed tends to be larger. The dynamic elastic modulus increases from $8.65 \mathrm{GPa}$ to $22.92 \mathrm{GPa}$, and both of them are larger than the elastic modulus of static uniaxial compression test of sandstone specimens $(5.42 \mathrm{GPa})$. This indicates that the larger the incident energy is, the greater the inertia force of the sandstone internal crystals will be. Therefore, the elastic modulus increases with the increase of incident energy. The ability of sandstone specimen to resist deformation under dynamic impact load can be significantly improved.

The fitting relation between dynamic elastic modulus $\left(E_{T}\right)$ and incident energy $\left(W_{I}\right)$ is shown as follows:

$$
E_{T}=0.001 W_{I}^{2}-0.206 W_{I}+17.098, \quad R^{2}=0.9838 \text {. }
$$

3.5. Strain Rate Effect of Specimen Dynamic Strength. In the SHPB impact compression test, the change of sandstone specimen strain rate under different incident energies is shown in Figure 16.

Figure 16 reveals that the dynamic strain rate is positively correlated with the incident energy as a quadratic function. 


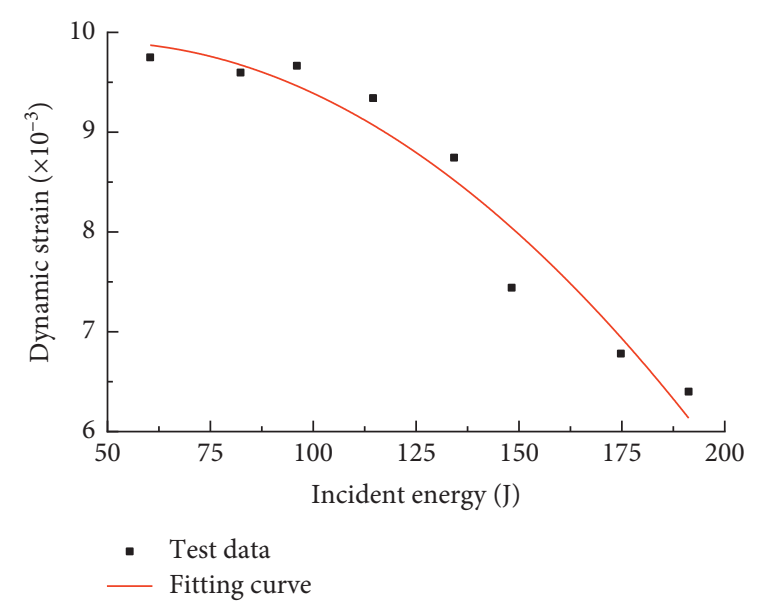

FIGURE 14: Relationship curve between dynamic strain and incident energy.

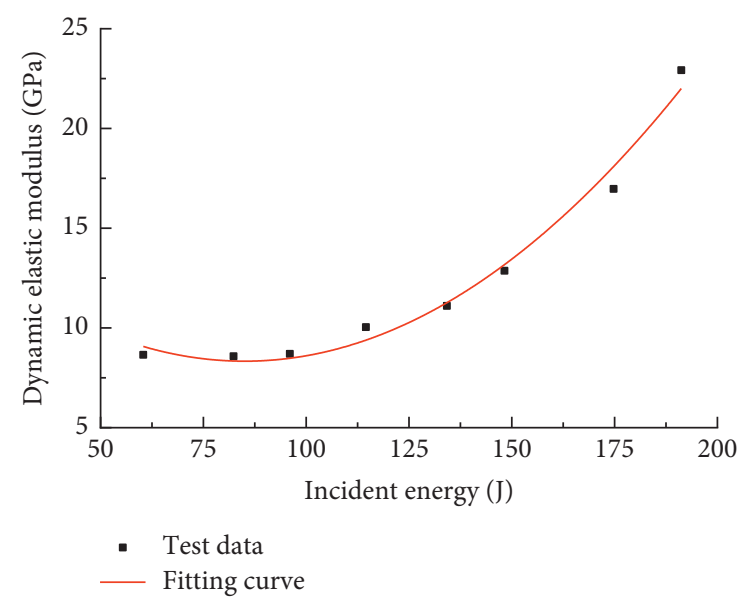

FIGURE 15: Relationship between dynamic elastic modulus and incident energy.

The fitting relation between strain rate $\left(\dot{\varepsilon}_{T}\right)$ and incident energy $\left(W_{I}\right)$ is shown as follows:

$$
\dot{\varepsilon}_{T}=0.0018 W_{I}^{2}+0.0271 W_{I}+87.8674, \quad R^{2}=0.9864 .
$$

The change of dynamic strength with strain rate is shown in Figure 17.

Figure 17 shows that the dynamic strength of the specimens increases along with the increase of strain rate, and when the strain rate difference is small, the dynamic strength performance is concentrated in the fitting curve. When strain rate increases rapidly, the dynamic performance of the strength is relatively dispersed, it can be noticed that the dynamic strength and strain rate show obvious strain rate effect.

The fitting relationship between dynamic strength $\left(\sigma_{T}\right)$ and strain rate $\left(\dot{\varepsilon}_{T}\right)$ is shown as follows:

$$
\sigma_{T}=0.9207 \dot{\varepsilon}_{T}^{0.9617}, \quad R^{2}=0.9807 .
$$

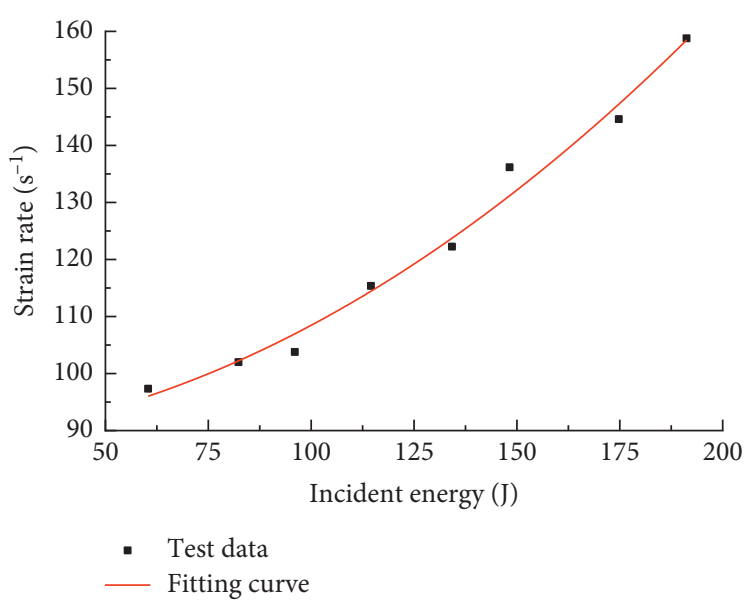

FIGURE 16: Relationship between strain rate and incident energy.

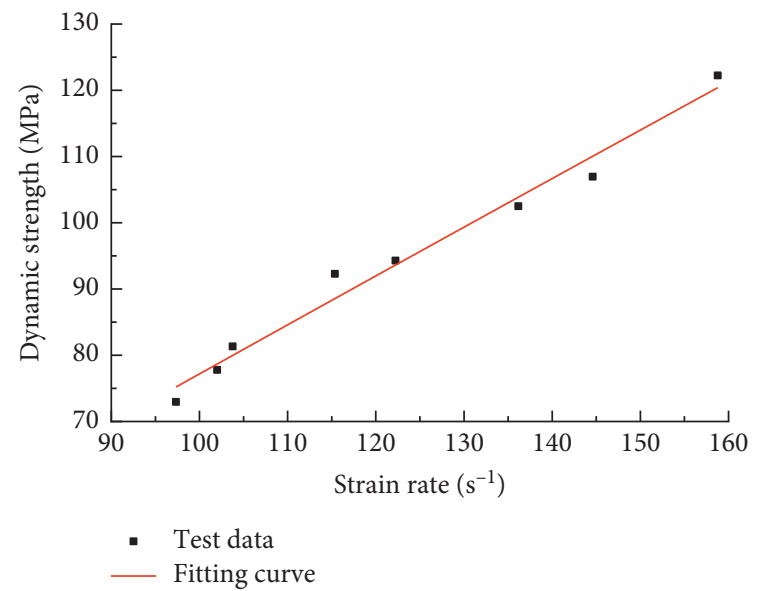

FIGURE 17: Relationship between dynamic strength and strain rate.

\section{Conclusion}

A $50 \mathrm{~mm}$ SHPB device was used to conduct impact compression tests of 8 loading rates on sandstone specimens in coal mine after 10 high temperature cycling times at $400^{\circ} \mathrm{C}$. The physical indexes, dynamic mechanical characteristics, and energy dissipation characteristics of sandstone specimens after high temperature cycling were studied and analyzed. The conclusions are as follows:

(1) With the increase of the number of high temperature cycles, the sandstone specimen gradually shows reddish brown spots. The mass, density, and longitudinal wave velocity all decrease with various amplitudes. In addition, the volume increase rate, mass decrease rate, density decrease rate, and longitudinal wave velocity decrease rate all show a quadratic function relationship with the number of cycles.

(2) The dynamic compressive stress-stress curve of sandstone specimens subjected to high temperature cyclic action under impact load is obviously different from that under normal temperature static load. It is embodied in the stress-strain curve of dynamic 
compression at the no-compression phase. The elastic modulus of dynamic curve is much higher than that under static load. The failure modes of sandstone specimens under dynamic and static loads show brittleness and ductility characteristics, respectively.

(3) In the impact compression test of SHPB, the impact pressure, the reflected energy, the transmitted energy, and the absorbed energy of the specimen all increased linearly with the incident energy. The dynamic strength, the dynamic elastic modulus, and the strain rate of sandstone specimens are positively correlated with the incident energy as a quadratic function, while the dynamic strain is negatively correlated with the incident energy as a quadratic function.

\section{Data Availability}

The data used to support the findings of this study are available from the corresponding author upon request.

\section{Conflicts of Interest}

The authors declare that there are no conflicts of interest regarding the publication of this paper.

\section{Acknowledgments}

This research received financial support from the National Natural Science Foundation of China (no. 51674008), Anhui Provincial Natural Science Foundation (no. 1808085ME134), Anhui Postdoctoral Science Foundation (no. 2015B058), Anhui University of Science and Technology Graduate Innovation Fund Project (no. 2019CX2026), and National College Student Innovation and Entrepreneurship Training Program (no. 201910361025). Thanks are due to the Research Center of Mine Underground Engineering, Ministry of Education, and State Key Laboratory of Mining Response and Disaster Prevention and Control in Deep Coal Mine, Anhui University of Science and Technology, for providing the experiment conditions.

\section{References}

[1] H. P. Xie, "Research review of the state key research development program of China: deep rock mechanics and mining theory," Journal of China Coal Society, vol. 44, no. 5, pp. 1283-1305, 2019.

[2] S. Liu and J. Xu, "Study on dynamic characteristics of marble under impact loading and high temperature," International Journal of Rock Mechanics and Mining Sciences, vol. 62, pp. 51-58, 2013.

[3] T. Yin, L. Bai, X. Li, and S. Zhang, "Effect of thermal treatment on the mode I fracture toughness of granite under dynamic and static coupling load," Engineering Fracture Mechanics, vol. 199, pp. 143-158, 2018.

[4] S. Liu and J. Xu, "Effect of strain rate on the dynamic compressive mechanical behaviors of rock material subjected to high temperatures," Mechanics of Materials, vol. 82, pp. 28-38, 2015.
[5] Y. L. Chen, W. Shao, and Y. C. Zhou, "Experimental study on mechanical properties of granite after high temperature," Chinese Quarterly of Mechanics, vol. 32, no. 3, pp. 397-402, 2011.

[6] S. J. Du, H. Liu, H. T. Zhi et al., "Testing study on mechanical properties of post-high-temperature granite," Chinese Journal of Rock Mechanics and Engineering, vol. 23, no. 14, pp. 2359-2364, 2004.

[7] H. H. Zhu, Z. G. Yan, T. Deng et al., "Testing study on mechanical properties of tuff, granite and breccia after high temperatures," Chinese Journal of Rock Mechanics and Engineering, vol. 25, no. 10, pp. 1945-1950, 2006.

[8] C. D. Su, S. J. Wei, B. D. Qin et al., "Experimental study of influence mechanism of high temperature on mechanical properties of fine-grained sandstone," Rock and Soil Mechanics, vol. 38, no. 3, pp. 623-630, 2017.

[9] R. Mao, X. Mao, L. Zhang, and R. Liu, "Effect of loading rates on the characteristics of thermal damage for mudstone under different temperatures," International Journal of Mining Science and Technology, vol. 25, no. 5, pp. 797-801, 2015.

[10] W. Zhang, Q. Sun, S. Hao, J. Geng, and C. Lv, "Experimental study on the variation of physical and mechanical properties of rock after high temperature treatment," Applied Thermal Engineering, vol. 98, pp. 1297-1304, 2016.

[11] C. Lü, Q. Sun, W. Zhang, J. Geng, Y. Qi, and L. Lu, “The effect of high temperature on tensile strength of sandstone," Applied Thermal Engineering, vol. 111, pp. 573-579, 2017.

[12] Q. Sun, C. Lü, L. Cao, W. Li, J. Geng, and W. Zhang, "Thermal properties of sandstone after treatment at high temperature," International Journal of Rock Mechanics and Mining Sciences, vol. 85, pp. 60-66, 2016.

[13] J. Y. Xu and S. Liu, "Effect of impact velocity on dynamic mechanical behaviors of marble after high temperatures," Chinese Journal of Geotechnical Engineering, vol. 35, no. 5, pp. 879-883, 2013.

[14] T. B. Yin, X. B. Li, Z. Q. Yin et al., "Study and comparison of mechanical properties of sandstone under static and dynamic loadings after high temperature," Chinese Journal of Rock Mechanics and Engineering, vol. 31, no. 2, pp. 273-279, 2012.

[15] P. Wang, J. Y. Xu, S. Liu et al., "Research on dynamic mechanical properties of sandstone at high temperature," Acta Armamentarii, vol. 34, no. 2, pp. 203-208, 2013.

[16] Q. Ping, M. J. Wu, P. Yuan et al., "Experimental study on dynamic mechanical properties of high temperature sandstone under impact loads," Chinese Journal of Rock Mechanics and Engineering, vol. 38, no. 4, pp. 782-792, 2019.

[17] M. J. Wu, Q. Ping, and H. Zhang, "Experimental study of effects of loading rates on sandstone dynamic mechanical properties at high temperature," Science Technology and Engineering, vol. 18, no. 24, pp. 281-287, 2018.

[18] X. H. Ni, X. J. Li, and D. W. Huang, "Uniaxial compression tests on mechanical properties of marble after undergoing different numbers of temperature cycling," Journal of $\mathrm{Hy}$ droelectric Engineering, vol. 35, no. 9, pp. 95-100, 2016.

[19] R. Wang, D. Y. Zhu, H. Y. Yao et al., "Influence of temperature on the mechanical performance of marble," Metal Mine, vol. 442, no. 4, pp. 49-53, 2013.

[20] R. Fang, Z. D. Zhu, Y. Zhang et al., "The study and comparison of the mechanical performance of marble under the action of high temperature and circle high temperature," Chinese Journal of Rock Mechanics and Engineering, vol. 24, no. 1, pp. 4735-4739, 2005.

[21] Z. Yin, W. Chen, H. Hao et al., "Dynamic compressive test of gas-containing coal using a modified split Hopkinson 
pressure bar system," Rock Mechanics and Rock Engineering, vol. 53, no. 2, pp. 815-829, 2020.

[22] Q. Ping, C. L. Zhang, H. P. Su, and H. Zhang, "Experimental study on dynamic mechanical properties and energy evolution characteristics of limestone specimens subjected to high temperature," Advances in Civil Engineering, vol. 2020, Article ID 8875568, 12 pages, 2020.

[23] L. L. Wang, Foundation of Stress Waves, pp. 39-64, National Defense Industry Press, Beijing, China, 2010.

[24] D. Ma, Q. Ma, Z. Yao, and K. Huang, "Static-dynamic coupling mechanical properties and constitutive model of artificial frozen silty clay under triaxial compression," Cold Regions Science and Technology, vol. 167, p. 102858, 2019.

[25] Q. Ping, Q. Y. Ma, and P. Yuan, "Energy dissipation analysis of stone specimens in SHPB tensile test," Journal of Mining and Safety Engineering, vol. 30, no. 3, pp. 401-407, 2013.

[26] S. Liu and J. Xu, "An experimental study on the physicomechanical properties of two post-high-temperature rocks," Engineering Geology, vol. 185, pp. 63-70, 2015.

[27] R. R. Zhang, L. W. Jing, and Q. Y. Ma, "Experimental study on thermal damage and energy evolution of sandstone after high temperature treatment," Shock and Vibration, vol. 2018, Article ID 3845353, 9 pages, 2018. 